Article

\title{
Awareness and Knowledge of Portugal Residents about Natura 2000
}

\author{
Sofia S. Oliveira ${ }^{1,2, *}$, Joana Pereira ${ }^{3 \oplus}$, Paulo Santos ${ }^{1,2}\left(\mathbb{D}\right.$ and Ruth Pereira ${ }^{2,4}(\mathbb{C}$ \\ 1 CIIMAR - Interdisciplinary Centre of Marine and Environmental Research, 4450-208 Matosinhos, Portugal; \\ ptsantos@fc.up.pt \\ 2 Department of Biology, Faculty of Sciences, University of Porto, 4169-007 Porto, Portugal; \\ ruth.pereira@fc.up.pt \\ 3 CESAM - Centre for Environmental and Marine Studies, Department of Biology, University of Aveiro, \\ 3810-193 Aveiro, Portugal; jpereira@ua.pt \\ 4 GreenUPorto-Sustainable Agrifood Production Research Centre, 4485-646 Vairão, Portugal \\ * Correspondence: oliveira.scds@gmail.com
}

Received: 9 October 2020; Accepted: 8 November 2020; Published: 19 November 2020

\begin{abstract}
Natura 2000 is the European Union's key strategy to address the current sharp decline in biodiversity. However, according to a recent survey, most Europeans have never heard about it. The present study intended to further explore the perceptions of residents in Portugal about this network of protected areas through the nationwide implementation of a survey. Overall, 232 questionnaires were fulfilled, which showed that most respondents $(n=126,54 \%)$ had never heard of Natura 2000. Furthermore, even the respondents who knew what Natura 2000 is were not well-informed about it. For instance, on average, they were only able to name $2.8 \pm 2.2$ sites within Portugal; plus, $66 \%(n=65)$ could not correctly name any wild species that inhabited their favourite site. Surprisingly, literacy levels were not significantly correlated with the number of visits to the network $\left(r_{\mathrm{s}}=0.181, p=0.082\right)$, and they were only weakly correlated with the frequency that the respondents engaged in ecological behaviours $\left(r_{\mathrm{S}}=0.277, p=0.007\right)$. Overall, the current findings are in agreement with similar studies carried out in Poland that revealed that the population was poorly informed about this important network of protected areas. This scenario is especially worrisome, considering that public participation is regarded as a key factor for successful nature conservation initiatives.
\end{abstract}

Keywords: wildlife; europe; pro-environment behaviour; questionnaire

\section{Introduction}

Despite its intrinsic value and its importance for human wellbeing, biodiversity is being lost at alarming rates worldwide [1,2]. To address this pressing issue, the European Union launched Natura 2000 - a coordinated network of protected areas. This network has a huge coverage, comprising more than $18 \%$ of the land of the European Union, plus $6 \%$ of its sea area [3,4]. Its goal is to ensure long-term protection of the most valuable and threatened species and habitats. This requires taking action to protect, maintain, or restore those species and habitats to a favourable conservation status [4,5]. Natura 2000 plans to fulfil its conservation mission through an inclusive and sustainable management approach. Hence, cooperation with all stakeholders is highly desirable. Additionally, this implies that socioeconomic activities compatible with site preservation are encouraged [4].

Despite Natura 2000's intentions to engage stakeholders, according to a survey carried out by the European Commission in 2018, most Europeans are still not aware of the existence of this network $(70 \%, N=27,643)$. The same study also reported that only $11 \%$ of respondents claimed to know what Natura 2000 is [6]. Plus, previous research carried out in Poland revealed that even the people 
who were aware of Natura 2000 knew little else about it [7-9], including members of the public that stated to be interested in environmental protection [9]. This suggests that this important network is still unknown to the majority of the European Union's population, which is a very worrisome finding as public participation plays a critical role in the achievement of biological conservation goals [2,10-13]. For instance, addressing the current drivers of biodiversity loss requires changes in citizens' behaviour [2]. Plus, people can pressure the government to take action, become involved in policy discussions, and also facilitate local conservation initiatives [2,10-12].

In Portugal, Natura 2000 is composed of 166 protected areas, covering almost $21 \%$ of the land area of the country [14]. Despite devoting such a large relative area to nature conservation [14], Portugal has failed to comply with some mandatory requirements regarding designation and management of the sites forming this network [15]. Due to this non-compliance, the European Commission referred Portugal to the Court of Justice of the European Union in January 2018 [15]. Furthermore, Portugal is also struggling with Natura 2000 monitoring demands. In fact, the country submitted the most incomplete Habitats Directive monitoring report among all Member States for the period 2007-2012. In this report, about 35\% of the mandatory data was absent or referred to as unknown [3]. Although Portugal found it rather difficult to fulfil all its network obligations [3,15], its residents seemed to be more aware of Natura 2000 than the average European. In the aforementioned survey carried out by the European Commission, $35 \%$ of respondents from Portugal claimed they had heard of Natura 2000 before, which stands at $5 \%$ higher than the average [6]. Curiously, according to the same survey, a higher percentage of people in Portugal were familiar with the term "biodiversity" when comparing with the average of the European Union $(74 \%>71 \%)$ or Poland's numbers $(74 \%>46 \%)$ [6]—a country where Natura 2000 literacy has been showed to be very limited [7-9]. Plus, $100 \%$ of the Portuguese respondents believed that humans have the responsibility to take care of Nature, which, once again, is slightly above the average of the European Union $(100 \%>96 \%)$ as well as Poland's percentage (100\% > 95\%) [6]. Given this rationale, the present study intended to further understand how knowledgeable the Portuguese population is about Natura 2000 and how their literacy compares to countries where the public seems less sensitized to biodiversity and environment-related issues.

\section{Materials and Methods}

A questionnaire on Natura 2000 was adapted from the literature $[6-9,16,17]$. This questionnaire was divided into five parts: (1) demographic data (age, gender, place of residency, education level, job/study field); (2) awareness about Natura 2000; (3) ecological behaviours; (4) nationally threatened species; and (5) knowledge about Natura 2000 and familiarity with its sites. These parts are described in further detail in Table S1 (available in the Supplementary Material). Only inquired people that claimed to know what Natura 2000 is fulfilled the last part of the questionnaire. Completing the first four parts of the questionnaire took usually less than $5 \mathrm{~min}$, while fulfilling the complete version took up to $15 \mathrm{~min}$. During 2019, this questionnaire was broadly disseminated through the internet (e.g., published on Facebook groups, shared by a national citizen science platform) and was also implemented in-person during a few science communication activities somewhat related to Natura 2000 (e.g., activity about soil quality under the scope of Universidade Júnior (https://universidadejunior.up.pt/); monitoring sessions of Lutra lutra inside and outside Natura 2000). In these events, the questionnaire was applied both before and after the activities. All collected data were codified and submitted to a quantitative analysis on Microsoft Office Excel (2002 version), consisting of the calculation of percentages and descriptive statistics (arithmetical averages, standard deviations). Plus, Spearman's correlations (more details in Table S1, in the Supplementary Material) were computed using IBM SPSS Statistics (version 26), in order to test the hypotheses described below: 
Hypothesis 1 (H1). People who visit Natura 2000 sites more often are better informed about the network.

Hypothesis 2 (H2). Respondents that are more informed about biodiversity in general (e.g., threatened species) are also more knowledgeable about this network of protected areas.

Hypothesis 3 (H3). Members of the public that engage more frequently in ecological behaviours have a higher Natura 2000 literacy.

\section{Results and Discussion}

Overall, 232 individuals participated in this study: 60 (26\%) fulfilled the questionnaires remotely, while $172(74 \%)$ completed it at face-to-face events. Despite the great dissemination efforts carried out on social media and by resorting to the authors' personal network of contacts, the number of questionnaires fulfilled online was very low. The authors attribute this situation, first, to the huge number of requests to fulfil questionnaires that are saturating the public online, a phenomenon highlighted by other authors [18]. Secondly, the unfamiliarity of the average internet user with the term "Natura 2000" and/or their lack of interest in the topic might have dissuaded them from reply.

\subsection{Sociodemographic Data}

As shown in Figure 1, most respondents were females aged between 12 and 29 (67\%,n=155). Regarding the geographical location of residence, Porto was the best represented district $(52 \%, n=121)$, followed by Aveiro $(16 \%, n=38)$, Braga $(9 \%, n=20)$, and Bragança $(9 \%, n=20)$, all from the centre and north of Portugal.

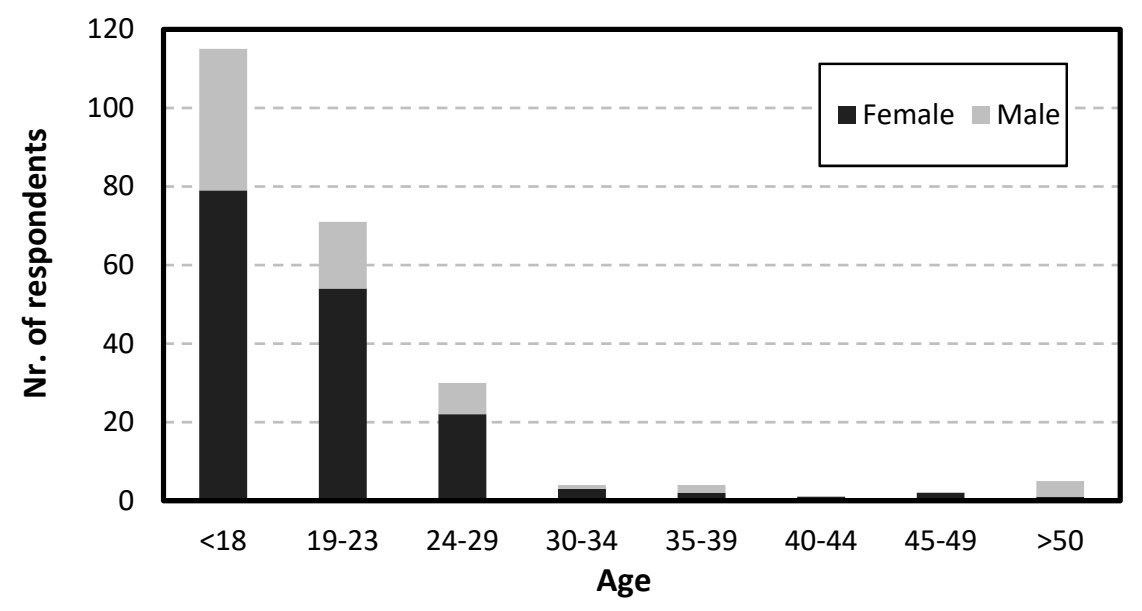

Figure 1. Age and Gender Distribution of Respondents.

Almost half of the participants were still attending middle school $(48 \%, n=111)$; but, a great number of questionnaires were also fulfilled by people who held a university degree $(29 \%, n=68)$ or a high school diploma $(22 \%, n=50)$. About $30 \%$ of participants $(n=70)$ had jobs or were pursuing studies related to biology and/or nature conservation.

\subsection{Awareness about Natura 2000}

As expected, based on the previous literature reports $[6,8,16]$, most respondents had never heard of Natura $2000(54 \%, n=126)$. However, $20 \%(n=47)$ had heard of the term beforehand and claimed to know what Natura 2000 is. This percentage is slightly higher than the one obtained for Portugal in the survey carried out by the European Commission $(20 \%>15 \%)$ [6]. This difference in percentages is likely due to a lower representativeness level of the sample, which is supported by the fact that $81 \%$ of respondents $(n=38)$ contributing to the " $20 \%$ result" studied or worked in fields related 
to biology and/or nature conservation. Furthermore, a high proportion of respondents, who knew what Natura 2000 is, held a university degree $(74 \%, n=35)$; in a similar study carried out in Poland, this population segment was shown to be more aware of the network than people who did not attend higher education [8]. Nonetheless, as the goal of the present research was to further explore the perceptions of respondents, this higher percentage of participants aware of Natura 2000 was welcome.

\subsection{Knowledge about Natura 2000 Sites}

The 47 respondents that claimed to know what Natura 2000 is were asked to name between one and ten Portuguese Natura 2000 sites. Overall, 39 distinct protected areas were named, which represented $23 \%$ of all network sites located in Portugal [14]. On average, each participant correctly named $2.8 \pm 2.2$ sites; but, this was highly variable, e.g., six participants named none and one mentioned 10 . Peneda/Gerês (PTCON0014) was the site mentioned by a higher number of participants; Serra da Estrela (PTCON0014) and Montesinho/Nogueira (PTCON0002) came second and third, respectively (Table 1). The overall low ability of respondents to name Natura 2000 sites in Portugal was not a surprising finding, since research in other countries showed that most inquired inhabitants were unaware of the existence of such protected areas in the vicinities of their household $[7,8]$.

The recording of Peneda/Gerês as the most mentioned site was expected as this is simultaneously the only national park in Portugal [19] and a very popular protected area in the country, as demonstrated by the fact that this is the one contacted by the highest number of visitants (more than 1 million visitor contacts/year during the period 1996-2019) [20]. The presence of Serra da Estrela in the top 3 was also expected; being the highest mountain range on the mainland [21], this site receives many visitors during Winter to enjoy snowfall [22]. However, the high number of people mentioning Montesinho/Nogueira is harder to explain. This situation may have occurred because this is one of the largest protected areas in northern Portugal [19], where most respondents were from.

Afterwards, respondents were asked to name their favourite Natura 2000 site along with some species that inhabit it (max. 10) as well as to select from a list the main threats that such protected area faces (max. 5). From this point on, unless otherwise stated, besides the 47 participants that said they knew what Natura 2000 is beforehand, the data analysis also included answers given to post tests by 99 respondents that claimed to already know what Natura 2000 is. Overall, 21 different sites were designated by participants as their personal favourites: Peneda/Gerês, Serra da Estrela, Ria de Aveiro, and Rios Sabor e Maçãs were the ones selected by most respondents $(65 \%, n=95)$; all the other sites were mentioned by up to four individuals.

Yet, how knowledgeable were the inquired people about their favourite Natura 2000 protected areas? Regarding the threats, the ones selected by more participants were: pollution $(30 \%, n=44)$, tourism/recreational activities $(28 \%, n=41)$, and climate change $(26 \%, n=38)$. In a survey recently carried out by the European Commission, pollution was also the threat that most Portugal inhabitants thought to be considerably affecting biodiversity; man-made disasters and climate change came second and third, respectively [6]. Thus, the current results align with the European Commission findings, especially considering that (1) man-made disasters were not an option in the questionnaire used in the scope of this work, and that (2) tourism/recreational activities were not included in the abovementioned literature [6].

To better understand their perceptions, a detailed analysis was performed focusing on threats to Peneda/Gerês, Serra da Estrela, Ria de Aveiro, and Rios Sabor e Maçãs (Table 2). On average, respondents who provided a valid answer selected correctly only $1.7 \pm 1.4$ threats (out of five). It is important to highlight that a response was deemed correct if the selected threat had a medium or high relevance to the respondent's favourite site. Pollution, tourism/recreational activities, and climate change were the threats selected by more participants (Table 2). However, according to the managing authorities, climate change is not a relevant threat in any of the analysed sites; pollution only has a low to medium relevance, and the relevance of tourism/recreational activities varies between none to medium [23]. In contrast, invasive alien species-which represent a highly relevant threat in two of the protected areas further scrutinised and has a medium relevance in the other ones [23]—were selected 
by just 19 participants (Table 2). Therefore, respondents did not seem to have a clear perception about the main factors threatening their favourite Natura 2000 site. Plus, it is worth noticing that in the previously mentioned European Commission assessment, invasive alien species were also the threat that less Portuguese respondents thought to be relevant [6].

Table 1. Portuguese Natura 2000 sites named by respondents, their respective site code, and number of participants mentioning each one $(N=47)$.

\begin{tabular}{llc}
\hline \multicolumn{1}{c}{ Natura 2000 Sites } & Site Code & $n$ \\
\hline Peneda/Gerês & PTCON0001 & 33 \\
Serra da Estrela & PTCON0014 & 12 \\
Montesinho/Nogueira & PTCON0002 & 9 \\
Alvão/Marão & PTCON0003 & 7 \\
Ria de Aveiro & PTCON0061 & 7 \\
Arrábida/Espichel & PTCON0010 & 5 \\
Litoral Norte & PTCON0017 & 5 \\
Sintra/Cascais & PTCON0008 & 4 \\
Douro Internacional & PTCON0022 & 3 \\
Estuário do Tejo & PTCON0009 & 3 \\
Malcata & PTCON0004 & 3 \\
Ria Formosa & PTZPE0017 & 3 \\
Rio Lima & PTCON0020 & 3 \\
Côrno do Bico & PTCON0040 & 2 \\
Costa Sudoeste & PTCON0012 & 2 \\
Estuário do Sado & PTCON0011 & 2 \\
Ilhas Berlengas & PTZPE0009 & 2 \\
Serras da Freita e Arada & PTCON0047 & 2 \\
Valongo & PTCON0024 & 2 \\
Barrinha de Esmoriz & PTCON0018 & 1 \\
Cabrela & PTCON0033 & 1 \\
Complexo do Açor & PTCON0051 & 1 \\
Dunas de Mira, Gândara e Gafanhas & PTCON0055 & 1 \\
Gardunha & PTCON0028 & 1 \\
Lagoa da Sancha & PTZPE0014 & 1 \\
Lagoa de Santo André & PTZPE0013 & 1 \\
Laurissilva da Madeira & PTMAD0001 & 1 \\
Maciço Montanhoso Central da Ilha da Madeira & PTMAD0002 & 1 \\
Monfurado & PTCON0031 & 1 \\
Montemuro & PTCON0025 & 1 \\
Paul de Arzila & PTCON0005 & 1 \\
Paul do Boquilobo & PTZPE0008 & 1 \\
Ria Formosa/Castro Marim & PTCON0013 & 1 \\
Rio Minho & PTCON0019 & 1 \\
Rio Vouga & PTCON0026 & 1 \\
Serras d'Aire e Candeeiros & & 1 \\
\hline & PTC015 & \\
\hline & & \\
\hline
\end{tabular}


Table 2. Main Threats to Each Natura 2000 Site, as Selected by Respondents $(N=95)$, and Threat Relevance (R) to the Respective site (H-high; M-medium; L-low; "-"-irrelevant threats).

\begin{tabular}{|c|c|c|c|c|c|c|c|c|c|}
\hline \multirow{2}{*}{ Threats } & \multicolumn{2}{|c|}{ Peneda/Gerês } & \multicolumn{2}{|c|}{ Serra da Estrela } & \multicolumn{2}{|c|}{ Ria de Aveiro } & \multicolumn{2}{|c|}{ Rios Sabor e Maçãs } & \multirow{2}{*}{ Total } \\
\hline & $\mathbf{R}$ & $n$ & $\mathbf{R}$ & $n$ & $\mathbf{R}$ & $n$ & $\mathbf{R}$ & $n$ & \\
\hline Agriculture/Grazing & M & 8 & - & 1 & $\mathrm{M}$ & 3 & $\mathrm{H}$ & 2 & 14 \\
\hline Forest plantations & $\mathrm{L}$ & 8 & $\mathrm{~L}$ & 2 & $\mathrm{M}$ & 2 & M & 0 & 12 \\
\hline Mining and extraction of materials & $\mathrm{L}$ & 3 & $\mathrm{~L}$ & 2 & $\mathrm{M}$ & 1 & M & 0 & 6 \\
\hline Energy production & $\mathrm{L}$ & 3 & - & 4 & - & 0 & - & 0 & 7 \\
\hline Transportation/service corridors & M & 9 & M & 7 & $\mathrm{H}$ & 3 & M & 1 & 20 \\
\hline Urbanization & M & 7 & $\mathrm{M}$ & 8 & $\mathrm{H}$ & 3 & - & 0 & 18 \\
\hline Fishing/Aquaculture & - & 6 & - & 0 & $\mathrm{H}$ & 4 & - & 5 & 15 \\
\hline Hunting (incl. collection of wild animals) & $\mathrm{H}$ & 12 & $\mathrm{~L}$ & 5 & $\mathrm{M}$ & 2 & M & 0 & 19 \\
\hline Removal of terrestrial plants & M & 6 & M & 1 & - & 0 & - & 5 & 12 \\
\hline Tourism/Recreational activities & M & 14 & $\mathrm{~L}$ & 10 & - & 4 & M & 0 & 28 \\
\hline Climate change & - & 9 & - & 11 & - & 4 & - & 0 & 24 \\
\hline Invasive alien species & $\mathrm{H}$ & 13 & $\mathrm{M}$ & 2 & $\mathrm{H}$ & 4 & M & 0 & 19 \\
\hline Pollution & $\mathrm{L}$ & 10 & $\mathrm{M}$ & 12 & $\mathrm{M}$ & 6 & $\mathrm{~L}$ & 0 & 28 \\
\hline Do not know/remember & & 10 & & 3 & & 1 & & 3 & 17 \\
\hline Invalid answers & & 5 & & 9 & & 1 & & 2 & 17 \\
\hline
\end{tabular}

A detailed analysis of the wild species that respondents thought to inhabit Natura 2000 protected areas was also performed, focusing only on the answers given by participants who elected Peneda/Gerês, Serra da Estrela, Ria de Aveiro, or Rios Sabor e Maçãs as their favourite site. Overall, 52 taxa were correctly named, with birds being the most well-represented group (Figure 2). All mentioned taxa were native, except for one: the common water hyacinth (Eichhornia crassipes), an invasive alien aquatic plant that is present in mainland Portugal and Azores [24].

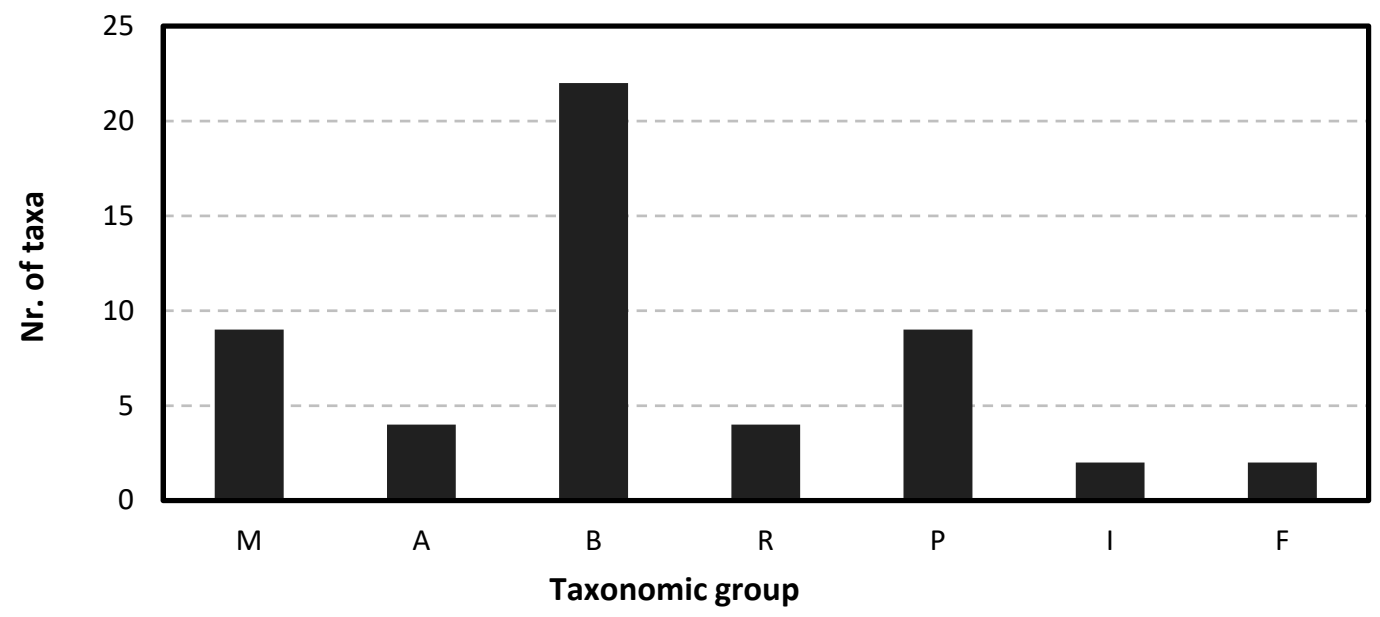

Figure 2. Number of Taxa That Respondents Correctly Indicated to Be Present at Their Preferred Natura 2000 Site, By Taxonomic Group. Taxonomic groups: M-mammals; A—amphibia; B—birds; $\mathrm{R}$-reptiles; P-plants; I-invertebrates; F-fish.

Most participants ( $n=65,66 \%$ ) were not able to name any species correctly (in order to assess if a given species was present—or not—in a specific Natura 2000 site, several sources were consulted [23-30]). The remaining respondents correctly mentioned, on average, $3.3 \pm 2.5$ taxa (out of 10). These numbers suggest they were not very familiar with the biodiversity of their favourite Natura 2000 sites. It is also worth mentioning that, regarding this question, many participants provided broad answers, referring to kingdoms, orders, or families (e.g., animals, plants, bats, ants); but, for the purpose of this work, only common names exclusively used for genera or species were considered.

These results are in accordance with similar studies carried out in Poland, which also revealed that the majority of people who were aware of what Natura 2000 is knew little else about it $[7,9]$. 


\subsection{Natura 2000 Visits}

Most respondents who were aware of what Natura 2000 is only visited it once per year or even less frequently (Figure 3). Regardless, the number of times participants visited this network was not significantly correlated with their knowledge about it $\left(r_{\mathrm{S}}=0.181, p=0.082\right)$. This is a surprising finding as it suggests that spending time more often at Natura 2000 sites has little improvement on visitors' knowledge about them. This may also suggest that there is a shortage of Natura 2000 information at the network sites and/or that people visit these sites mostly for leisure and their landscape value.

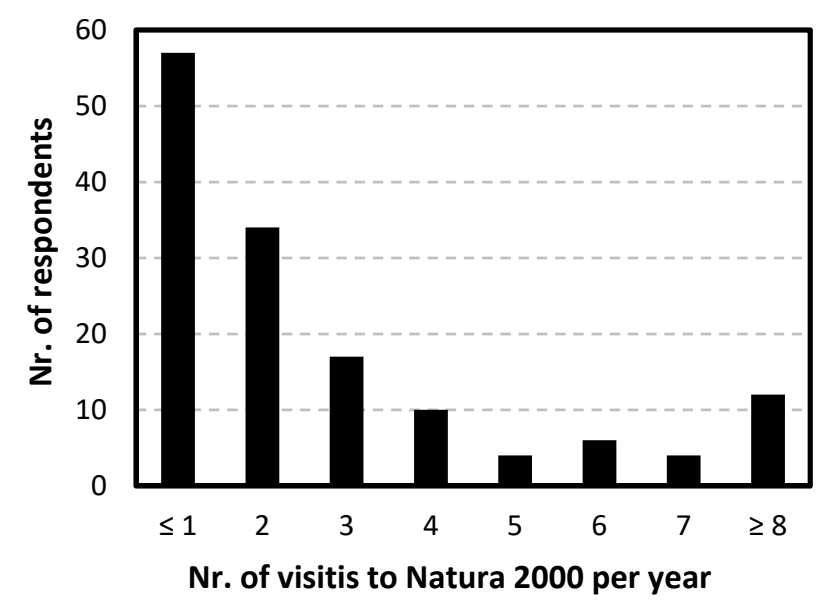

Figure 3. Number of Self-Reported Visits to Natura 2000, per Year $(N=144)$.

\subsection{Knowledge about Threatened Species}

Each participant, on average, correctly named $1.7 \pm 1.2$ taxa (out of 10) that were threatened with extinction in Portugal (conservation status was checked in the Portuguese Red Book of Vertebrates [25] and on Flora-On [24]). In total, 33 nationally threatened taxa were mentioned, with most of them being mammals $(n=12,36 \%)$ or birds $(n=11,33 \%)$. However, currently, there are 568 taxa classified as threatened with extinction in Portugal $[24,25]$, which means that the replies given by the sampled population represent only around $6 \%$ of the total specific richness. Previous studies carried out in Portugal, targeting high school students, revealed that overall, this audience was poorly informed about national threatened species [31-33]. Despite the sample of the present research comprising a large proportion of students, $30 \%$ of the respondents were working or pursuing studies related to biology and/or nature conservation; therefore, a higher literacy about threatened species was expected. The Iberian lynx (Lynx pardinus), Iberian wolf (Canis lupus signatus), and Spanish imperial eagle (Aquila adalberti) were the ones referred by more participants (Figure 4). All the other taxa were only named by up to seven respondents. This might be related to the fact that charismatic species (e.g., wolfs and tigers [34]) are disproportionately more often targeted by conservation actions as well as by public awareness efforts [35,36]. Although some of these species hold a high conservation value, since they can effectively act as an umbrella for the protection of other taxa [37-39], this is not true for all charismatic species [37,40]. Their keystone role in the ecosystem and/or their large home range are two characteristics widely shared by charismatic species that can function as surrogates for the preservation of other biodiversity [41]. However, this charismatic-based strategy may limit the pool of conservation issues that the public is exposed to [35]. Plus, the authors of a recent study argued that the wide overrepresentation of charismatic species in Western culture (e.g., magazines [35], social media [42]) seems to be responsible for a biased public perception regarding their conservation status, making them appear more abundant than what they are in reality [34]. Hence, the present results showing disparity in awareness about different threatened species in Portugal is very intriguing and should be further studied. Regardless, it is relevant to highlight that in other studies that took place in Portugal, the majority of the inquired high school students were unaware of the main factor leading to the reduction in population size of the Iberian lynx (L. pardinus) [31-33]. Therefore, even though 
this was the national threatened species mentioned by the most participants in the scope of the present work, this should not be interpreted as evidence that they were well-informed about it. Finally, the number of threatened taxa mentioned by respondents was weakly correlated with their knowledge about Natura $2000\left(r_{\mathrm{s}}=0.393, p=0.000\right)$.

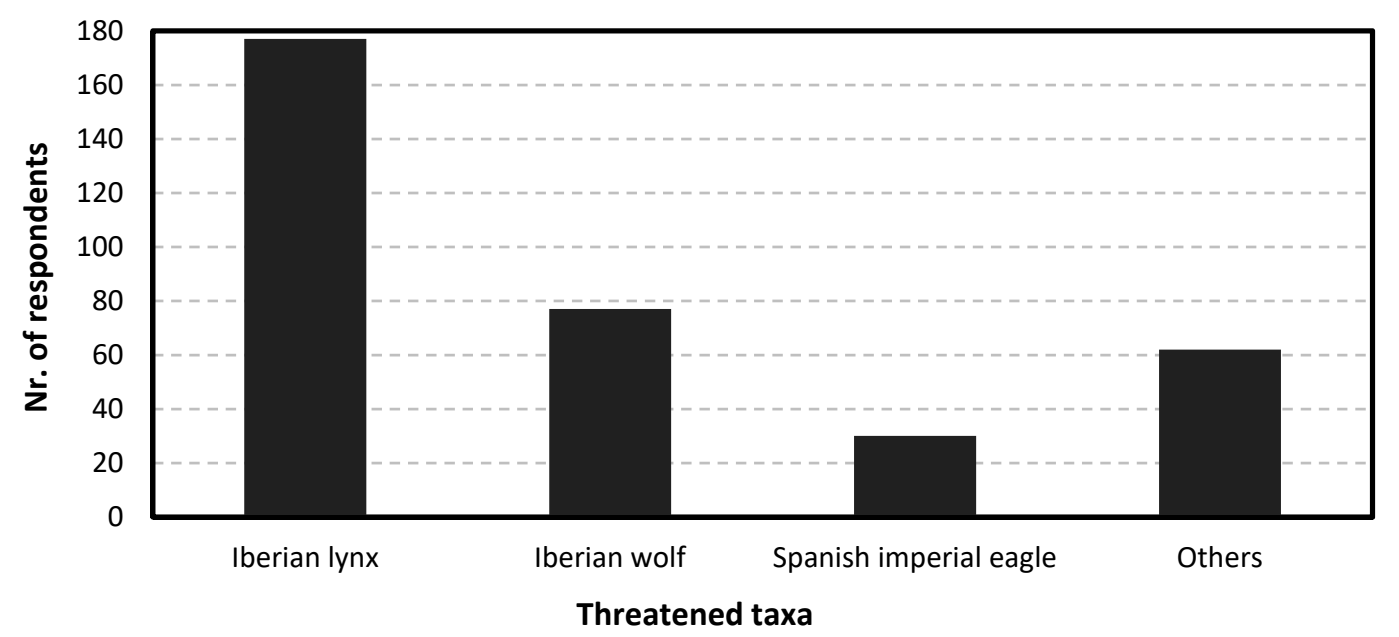

Figure 4. Threatened taxa in Portugal that were mentioned by respondents $(N=232)$.

\subsection{Pro-Environment Behaviours}

Taking part in citizen science projects was the behaviour participants showed less frequently (Table 3), which indicates this was the most difficult task to accomplish for the sampled population [17]. This may be related to the fact that citizen science is still at its infancy in the country [43,44]. In contrast, reusing shopping bags, having a shower, and depositing garbage in the appropriate recycling bins seemed to be easier behaviours to adopt [17]. The relative ease of engaging in these behaviours was already documented for other populations worldwide $[7,9,17]$. Concerning recycling habits, the present finding is in accordance with a nationwide inquiry carried out in 2019, where $89 \%$ of the questioned people self-reported to adopt such behaviour [45]. However, in the last few years, the recycling rate of municipal waste in Portugal was far below the average of the European Union [46]. This suggests that Portugal residents may not be recycling properly.

The frequency of ecological behaviours was poorly correlated with the respondents' knowledge about Natura $2000\left(r_{\mathrm{s}}=0.277, p=0.007\right)$. Increasing the public's knowledge about biodiversity is widely considered necessary to foster the willingness to adopt pro-environment behaviours [2,47]; however, this study failed to show a strong correlation between Natura 2000 knowledge and engagement in ecological behaviours. This may be due to the fact that knowledge about the network is restricted to people highly literate about biological diversity, which is supported by our records that (i) in this study, $81 \%$ of respondents who were aware of Natura 2000 worked or pursued studies related to biology or nature conservation ( $n=38$ ); (ii) $74 \%$ of respondents that claimed to know what Natura 2000 is held at least one university degree $(n=35)$. This explanation is also supported by the results of a survey published by the European Commission in 2015, which revealed that Natura 2000 was unknown even for $39 \%$ of Europeans that self-reported to be well-informed about biodiversity loss [16]. 
Table 3. Average frequency with which respondents engaged in the ecological behaviours described above $(N=232)$.

\begin{tabular}{ccc}
\hline Ecological Behaviour & Average Frequency & $\begin{array}{c}\text { SD } \\
\text { (Standard Deviation) }\end{array}$ \\
\hline Depositing garbage in the appropriate recycling bin & 4.3 & 0.9 \\
\hline Reusing shopping bags & 4.6 & 1.2 \\
\hline Avoiding buying single use plastics & 3.6 & 1.1 \\
\hline Talking to others about environmental issues and Nature in general & 3.5 & 1.2 \\
\hline Being involved in environmental restoration actions & 2.6 & 1.1 \\
\hline $\begin{array}{c}\text { (e.g., tree plantations) } \\
\text { orticipating in citizen science initiatives targeting Nature and/ }\end{array}$ & 2.2 & 1.2 \\
\hline Having a shower instead of a bath & 4.4 \\
\hline
\end{tabular}

A 5-point Likert scale was used by participants to indicate the frequency with which they adopted pro-environment behaviours (1-never; 2-rarely; 3-sometimes; 4-often; 5-regularly).

\section{Conclusions}

Although this network of protected areas intends to fulfil its conservation goals while engaging stakeholders in the management process, previous studies have showed that Natura 2000 is still unknown by a large majority of Europeans. This can undermine its conservation mission, as public participation is considered a crucial factor for successful nature conservation initiatives [2,10-13]. The present study demonstrated that in Portugal, even the people aware of Natura 2000's existence knew little else about it. For instance, respondents could only name a very restricted number of sites belonging to this network. Furthermore, participants had very limited knowledge regarding the species inhabiting their favourite site as well as the main factors threatening it. Therefore, despite a recent Eurobarometer showing that the Portuguese population is more familiar with biodiversity and Natura 2000 than the average of the European Union [6], Natura 2000 knowledge was still found to be rather restricted. Plus, similar conclusions were reached for Poland. The limited literacy levels detected are especially worrisome, given that the current study had an overrepresentation of people who were expected to be highly literate in the topics of the survey. It is also worth highlighting that no statistically significant correlation was found between Natura 2000 literacy and the annual number of visits to this network. This raises the important question of whether these protected areas have enough conservation-related activities and/or information displayed on-site. The bottom line is that the current paper is another testimony of the urgent need for the improvement of science communication efforts focusing on Natura 2000, with the ultimate aim of enhancing its performance regarding species and habitats conservation. Overall, no significant strong correlation was found between the knowledge about nationally threatened species and Natura 2000 literacy or the adoption frequency of ecological behaviours.

Supplementary Materials: The following are available online at http://www.mdpi.com/2071-1050/12/22/9663/s1, Table S1: Sections (and sub-sections) of the implemented questionnaire and the respective number as well as type of questions included in each one.

Author Contributions: Conceptualization, S.S.O., J.P., P.S. and R.P.; investigation, S.S.O.; methodology, S.S.O., J.P., P.S. and R.P.; project administration, J.P., P.S. and R.P.; supervision, J.P., P.S. and R.P.; validation, S.S.O.; visualization, S.S.O.; writing-original draft, S.S.O.; writing-review and editing, J.P., P.S. and R.P. All authors have read and agreed to the published version of the manuscript.

Funding: This work was supported by the Portuguese Foundation for Science and Technology (FCT) under the PhD scholarship SFRH/BD/129529/2017. Thanks are due for the financial support by FCT/MCTES to CESAM (UIDP/50017/2020+UIDB/50017/2020) and GreenUPorto (UIDB/05748/2020 and UIDP/05748/2020), to FCT/MCTES through national funds, and JL Pereira is funded by national funds, through FCT, in the scope of the framework contract foreseen in art. 23 of the Decree-Law 57/2016, changed by Law 57/2017. This research was also conducted under the project AgriFood XXI-NORTE-01-0145-FEDER-000041, financed by European Regional Development Fund (FEDER) through North Portugal Regional Operational Programme (Norte 2020). The APC was funded through the financial support provided to the project AgriFood XXI. 
Acknowledgments: The authors would like to thank all the participants involved in this study for taking the time to fill in the questionnaire.

Conflicts of Interest: The authors declare no conflict of interest. The funders had no role in the design of the study; in the collection, analyses, or interpretation of data; in the writing of the manuscript, or in the decision to publish the results.

\section{References}

1. Millennium Ecosystem Assessments. Ecosystems and Human Well-Being: Biodiversity Synthesis; World Resources Institute: Washington, DC, USA, 2005.

2. Convention on Biological Diversity. Global Biodiversity Outlook 4; Secretariat of the Convention on Biological Diversity: Montréal, QC, Canada, 2014; ISBN 92-9225-539-8.

3. European Court of Auditors. More Efforts Needed to Implement the Natura 2000 Network to Its Full Potential. Special Report; Publications Office of the European Union: Luxembourg, 2017. [CrossRef]

4. Sundseth, K. The EU Birds and Habitats Directives: For Nature and People in Europe; Publications Office of the European Union: Luxembourg, 2015. [CrossRef]

5. Management of Natura 2000 Sites. Available online: https:/ec.europa.eu/environment/nature/natura2000/ management/guidance_en.htm (accessed on 15 May 2020).

6. European Commission. Special Eurobarometer 481-Attitudes of Europeans towards Biodiversity; Kantar Public Brussels: Brussels, Belgium, 2019. [CrossRef]

7. Gotkiewicz, W.; Sternik, P. Environmental Awareness Among the Rural Population in Natura 2000 Areas, with Bartoszyce and Sorkwity Communes as an Example. Environ. Prot. Nat. Resour. 2014, 25, 77-81. [CrossRef]

8. Pietrzyk-Kaszyńska, A.; Cent, J.; Grodzińska-Jurczak, M.; Szymańska, M. Factors influencing perception of protected areas-The case of Natura 2000 in Polish Carpathian communities. J. Nat. Conserv. 2012, 20, $284-292$. [CrossRef]

9. Głabiński, Z. Ecological awareness of tourists in the coastal areas of Poland-Preliminary results of the survey. Bull. Geogr. Socioecon. Ser. 2015, 28, 53-68. [CrossRef]

10. McKinley, D.C.; Miller-Rushing, A.J.; Ballard, H.L.; Bonney, R.; Brown, H.; Cook-Patton, S.C.; Evans, D.M.; French, R.A.; Parrish, J.K.; Phillips, T.B.; et al. Citizen science can improve conservation science, natural resource management, and environmental protection. Biol. Conserv. 2017, 208, 15-28. [CrossRef]

11. Ruddy Duck Project. Eradication of Ruddy Ducks in the UK to Protect the White-Headed Duck. Available online: http://www.nonnativespecies.org/index.cfm?pageid=244 (accessed on 14 September 2020).

12. Beachy, J.R.; Neville, R.; Arnott, C. Successful control of an incipient invasive amphibian: Eleutherodactylus coqui on $\mathrm{O}^{\prime} \mathrm{ahu}, \mathrm{Hawai} i$. In Island Invasives: Eradication and Management, Proceedings of the International Conference on Island Invasives, Auckland, New Zealand, 8-12 February 2010; Veitch, C.R., Clout, M.N., Towns, D.R., Eds.; IUCN and Centre for Biodiversity and Biosecurity (CBB): Gland, Switzerland; Auckland, New Zealand, 2011; pp. 140-147.

13. Kati, V.I.; Hovardas, T.; Dieterich, M.; Ibisch, P.L.; Mihok, B.; Selva, N. The Challenge of Implementing the European Network of Protected Areas Natura 2000. Conserv. Biol. 2014, 1-10. [CrossRef] [PubMed]

14. Natura 2000 Data-The European Network of Protected Sites. Available online: https://www.eea.europa.eu/ data-and-maps/data/natura-11 (accessed on 15 May 2020).

15. Commission Refers Portugal to Court over Its Failure to Adequately Protect Natural Habitats and Species. Available online: https://ec.europa.eu/commission/presscorner/detail/en/IP_18_356 (accessed on 14 September 2019).

16. European Commission. Special Eurobarometer 436: Attitudes of Europeans towards the Issue of Biodiversity (Wave 4); TNS Political \& Social [Producer]: Brussels, Belgium, 2015. [CrossRef]

17. Kaiser, F.G.; Wilson, M. Assessing People's General Ecological Behavior: A Cross-Cultural Measure. J. Appl. Soc. Psychol. 2000, 30, 952-978. [CrossRef]

18. Porter, S.R.; Whitcomb, M.E.; Weitzer, W.H. Multiple surveys of students and survey fatigue. Neww Dir. Inst. Res. 2004, 121, 63-73. [CrossRef]

19. Rede Nacional de Áreas Protegidas. Available online: http://www2.icnf.pt/portal/ap/rnap (accessed on 14 September 2020).

20. $\mathrm{N}^{\circ}$ de Visitantes que Contactaram as Áreas Protegidas. Available online: https://www.icnf.pt/api/file/doc/ cef53d5079576383 (accessed on 15 May 2020). 
21. Parque Natural da Serra da Estrela. Available online: http://www2.icnf.pt/portal/ap/p-nat/pnse (accessed on 14 September 2020).

22. Teodoro, A.F.G. O Sucesso do Turismo no Espaço Rural da Serra da Estrela: Realidades e Utopias. Master's Thesis, Instituto Politécnico de Coimbra_Escola Superior Agrária, Coimbra, Portugal, 2015.

23. Natura 2000 Network Viewer. Available online: http://natura2000.eea.europa.eu/ (accessed on 15 May 2020).

24. Flora-on. Available online: https://flora-on.pt/ (accessed on 15 May 2020).

25. Cabral, M.J.; Almeida, J.; Almeida, P.R.; Delliger, T.; Ferrand de Almeida, N.; Oliveira, M.E.; Palmeirim, J.M.; Queirós, A.I.; Rogado, L.; Santos-Reis, M. (Eds.) Livro Vermelho dos Vertebrados de Portugal; Instituto da Conservação da Natureza: Lisboa, Portugal, 2005; ISBN 978-972-37-1082-3.

26. Loureiro, A.; Ferrand de Almeida, N.; Carretero, M.A.; Paulo, O.S. (Eds.) Atlas dos Anfíbios e Répteis de Portugal; Instituto da Conservação da Natureza e da Biodiversidade: Lisboa, Portugal, 2008; ISBN 9789896800055.

27. Bencatel, J.; Sabino-Marques, H.; Álvares, F.; Moura, A.E.; Barbosa, A.M. Atlas de Mamíferos de Portugal, 2nd ed.; Universidade de Évora: Évora, Portugal, 2019; ISBN 978-989-8550-80-4.

28. BioDiversity4All. Available online: https://www.biodiversity4all.org/ (accessed on 15 May 2020).

29. Vaca-Loura.pt: Resultados. Available online: http://www.vacaloura.pt/resultados/ (accessed on 15 May 2020).

30. Aves de Portugal. Available online: http://www.avesdeportugal.info/avesdeportugal-alfab.html (accessed on 15 May 2020).

31. Pedro, A.P.E.D. Monitorização da Literacia Ambiental nos Alunos Finalistas do Ensino Secundário. Master's Thesis, Faculty of Sciences-University of Porto, Porto, Portugal, 2009.

32. Cordeiro, F.B.; Pedro, A.D.; Moura, A.P.; Santos, P.T.; Azeiteiro, U.M. Literacia ambiental no Ensino Secundário. Captar 2013, 4, 27-56. [CrossRef]

33. Gomes, G.F.B.; Santos, P.T.; Azeiteiro, U.M. A literacia ambiental dos alunos finalistas do Ensino Secundário: O caso da Escola Secundária da Moita. Captar 2014, 5, 1-21. [CrossRef]

34. Courchamp, F.; Jaric, I.; Albert, C.; Meinard, Y.; Ripple, W.J.; Chapron, G. The paradoxical extinction of the most charismatic animals. PLoS Biol. 2018, 16, e2003997. [CrossRef]

35. Clucas, B.; McHugh, K.; Caro, T. Flagship species on covers of US conservation and nature magazines. Biodivers. Conserv. 2008, 17, 1517-1528. [CrossRef]

36. Sitas, N.; Baillie, J.E.M.; Isaac, N.J.B. What are we saving? Developing a standardized approach for conservation action. Anim. Conserv. 2009, 12, 231-237. [CrossRef]

37. Bennett, J.R.; Maloney, R.; Possingham, H.P. Biodiversity gains from efficient use of private sponsorship for flagship species conservation. Proc. R. Soc. B 2015, 282, 20142693. [CrossRef] [PubMed]

38. McGowan, J.; Beaumont, L.J.; Smith, R.J.; Chauvenet, A.L.M.; Harcourt, R.; Atkinson, S.C.; Mittermeier, J.C.; Esperon-Rodriguez, M.; Baumgartner, J.B.; Beattie, A.; et al. Conservation prioritization can resolve the flagship species conundrum. Nat. Commun. 2020, 11, 994. [CrossRef]

39. Sergio, F.; Newton, I.; Marchesi, L. Top predators and biodiversity. Nature 2005, 436, 192. [CrossRef]

40. Andelman, S.J.; Fagan, W.F. Umbrellas and flagships: Efficient conservation surrogates or expensive mistakes? Proc. Natl. Acad. Sci. USA 2000, 97, 5954-5959. [CrossRef]

41. Caro, T.M.; O'Doherty, G. On the Use of Surrogate Species in Conservation Biology. Conserv. Biol. 1999, $13,805-814$. [CrossRef]

42. Kidd, L.R.; Gregg, E.A.; Bekessy, S.A.; Robinson, J.A.; Garrard, G.E. Tweeting for their lives: Visibility of threatened species on Twitter. J. Nat. Conserv. 2018, 46, 106-109. [CrossRef]

43. Chandler, M.; See, L.; Copas, K.; Bonde, A.M.Z.; López, B.C.; Danielsen, F.; Legind, J.K.; Masinde, S.; Miller-Rushing, A.J.; Newman, G.; et al. Contribution of citizen science towards international biodiversity monitoring. Biol. Conserv. 2017, 213, 280-294. [CrossRef]

44. Barros, B.; Oliveira, S.S.; Pereira, J.; Santos, P.; Pereira, R. Caracterização do papel dos social media em projetos de ciência cidadã ligados à biodiversidade. Captar 2019, in press.

45. Hábitos de Reciclagem-Observatório de Tendências. Hábitos e Atitudes dos Portugueses face à Reciclagem de Resíduos. Available online: http://www.novoverde.pt/documentacao-estatisticas (accessed on 28 October 2020). 
46. Eurostat Data Browser: Recycling Rate of Municipal Waste. Available online: https://ec.europa.eu/eurostat/ databrowser/view/t2020_rt120/default/table?lang=en (accessed on 28 October 2020).

47. Levine, D.S.; Strube, M.J. Environmental Attitudes, Knowledge, Intentions and Behaviors Among College Students. J. Soc. Psychol. 2012, 152, 308-326. [CrossRef] [PubMed]

Publisher's Note: MDPI stays neutral with regard to jurisdictional claims in published maps and institutional affiliations.

(C) 2020 by the authors. Licensee MDPI, Basel, Switzerland. This article is an open access article distributed under the terms and conditions of the Creative Commons Attribution (CC BY) license (http://creativecommons.org/licenses/by/4.0/). 